\title{
AC 2007-1157: RESEARCH INFRASTRUCTURE CHALLENGES FOR GRADUATE PROGRAMS IN STEM DISCIPLINES AT MINORITY INSTITUTIONS
}

\section{Mohan Aggarwal, Alabama A\&M University}

Mohan Aggarwal is a professor and chairman of physics department at Alabama A\&M University. He received his master's degree from Roorkee University in 1968 and Ph.D. degree from Calcutta University in 1974. He then did his post doctoral research at Pennsylvania State University and Alabama A\&M University before joining the faculty at Alabama A\&M University in 1983. He is the author or co-author of more than 146 research publications in various research journals and has also published a book chapter entitled "Photonic Crystals: crystal growth processing and physical properties" in Handbook of Advanced Electronic and Photonic Materials and Devices Vol.9 Nonlinear Optical Materials in 2001 by Academic Press. His research interests include growth and crystallization of a variety of single crystals using melt growth techniques such as Czochralski technique and Bridgman Stockbarger techniques. His present interests are in the growth of piezoelectric PMN-PT crystals and recently developed lanthanum bromide scintillator crystals for nuclear countermeasures and astrophysics applications. Other interests are researching various methods to motivate students for learning physics. He is a member of various professional societies such as American Physical society, American Vacuum Society, thermal analysis society and others. A number of graduate students have pursued their graduate studies leading to their Master's and Doctoral degrees in physics from Alabama A\&M University under his guidance. He has been selected in NASA Administrator's Fellowship Program cohort 10 and is serving at Marshall Space Flight Center during 2006-2007.

\section{Benjamin Penn, NASA/Marshall Space Flight Center}

Dr. Benjamin Penn is a research scientist at NASA G.C. Marshall Space Flight Center in spacecraft and vehicle systems department. Dr. Penn earned his Bachelor's degree in biology from Winston Salem State University in 1969, Masters in Chemistry from Rensselaer polytechnic Institute in 1973 and his doctoral degree in fiber and polymer science from North Carolina State University in 1978. Dr Penn has more than 73 publications, 40 presentations and two patents involving the synthesis of nonlinear optical materials, growth of single crystals from melt and solution, growth of thin films by vapor deposition, colloidal crystals, preparation of silicon carbide-silicon nitride fibers by the pyrolysis of polymer precursors, fiber reinforced composites, and biodegradable polymers. Dr Penn served as Chairman of the NASA Technical Review Committee (TRC) for the "Alliance for Nonlinear Optics" (ANLO), which was funded by NASA. The ANLO, which was led by New Mexico Highlands University, consisted of three Hispanic Serving Institutions, three HBCUs and one majority institution. In addition he served on the TRC for Clark Atlanta University and Fisk University. Dr Penn has served as an advisor in the Summer High School Apprenticeship Program, Undergraduate Researchers Program, and Graduate Student Researchers Program. He has also served on the Graduate study committee of more than 5 Ph.D. and six M.S. students in the physics department at Alabama A\&M University. He has received three NASA awards for educational outreach involving Minority Institutions, including the Director's commendation Award in 2000. Dr Penn was selected for a NASA's Administrator's Fellowship award and served for one year as Cohort 6 at Alabama A\&M University during 2002-2004.

\section{Ravindra Lal, Alabama A\&M University}

Dr. Ravindra Behari Lal, University Eminent Scholar and Professor of Physics at Alabama A\&M University joined Alabama A\&M University in 1975. He also served as the chairperson of the department of physics. He obtained his M.S. and Ph.D. degrees in Solid State Physics from Agra University, India in 1958 and 1963 respectively. He did his postdoctoral work at NASA/Marshall Space Flight Center as a postdoctoral associate of National Academy of the Sciences/National Research Council. At NASA/MSFC he did pioneer work on the effects of radiation on thermal 
control coatings used for Apollo and other spacecrafts under the leadership NASA/MSFC director Dr. Werner Von Braun. He was selected for one year from 2004 to 2005 as a NASA's Administrator's Fellow to work in the Exploration Science and Technology Division of NASA/Marshall Space Flight Center.

While at AAMU he was chosen by NASA in 1978 as a principal investigator for a Space Shuttle experiment on the maiden flight of the Spacelab-3 mission in 1985. The crystal growth experiment for growing triglycine sulfate (TGS) crystals for room temperature infrared detectors was successfully flown. This work gave recognition to AAMU in the field of microgravity research. The success of the first experiment in 1985 gave Dr. Lal an opportunity to fly another experiment in 1992 on the First International Microgravity Laboratory (IML-I) to grow crystals of TGS using the Fluids Experiment System (FES).

The Alabama House of Representatives recognized him on April 25, 1985 for his achievements on NASA's Spacelab-3 experiment. In 1986, James C. Fletcher, NASA's Administrator, presented him with NASA's Public Service Achievement Award for Spacelab-3 Payload Principal Investigator's Team. Dr. Lal was a major contributor in the establishment of the M.S. and Ph.D. programs in Optics/Lasers and Materials Science at AAMU. He played a significant role in the winning proposal from the National Science Foundation Center on Nonlinear Optics and Materials and served as one of the PI's for this $\$ 1$ million/year center.

During his tenure at AAMU Dr. Lal has obtained over \$7 million in research funding. Presently, he is a principal investigator for grants from DOE, Air Force, and NSF. He has served as conference chairs for many SPIE (International Society for Optical Engineering) conferences. $\mathrm{He}$ is served as a co-chair in 2004 of the SPIE Presidential Advisory Committee on India.

In 2002 Dr. Lal was elected as a Fellow of the SPIE (The International Society for Optical Engineering), a distinction given to about 500 members out of a total of 17000 members of SPIE. $\mathrm{He}$ is also member of the American Association of Crystal Growth, American Physical Society, and Sigma XI. He was awarded the NASA New Technology Award in 1981 and 1983. He has given invited talks in Russia, Austria, India, Japan, including the Gordon Conferences in USA. He has published over 100 research papers in national and international journals. 


\title{
Research Infrastructure Challenges for Graduate Programs in STEM Disciplines at Minority Institutions
}

\begin{abstract}
It is much more challenging to perform experimental research functions at many minority institutions, because of lack of adequate research infrastructure. This is especially true if one wishes to initiate and implement masters and doctoral degree programs in physics. In the present paper, an attempt is made to discuss the various hurdles encountered by the authors in the establishment of Master's and Doctoral degree programs in physics at Alabama A\&M University, one of the HBCUs (Historically Black Colleges and Universities). The department got no special or necessary treatment and faculty members were asked to teach as much course work as any other undergraduate department on the campus. It was very hard to convince university administration that giving less teaching load to research producing department faculty, shall culminate in abundant funding for the future years. This scenario created an extra heavy pressure on the faculty to continue the program. Some of the challenges included the resistance of some faculty and administrators to change, lack of sufficient release time for research producing faculty, and potential variation in funding or support with changes in the state education budget proration or members of the administration. In spite of the indirect cost recovery, very little infrastructure facilities was provided and the federal funding agencies did not want to interfere in the administration of the university. Various issues of recruiting and mentoring minority students, retention in the STEM disciplines as well as research infrastructure challenges at an HBCU university are presented.
\end{abstract}

\section{Introduction}

Alabama A\&M University is one of the HBCUs (Historically Black Colleges and Universities) and established a separate department of physics in 1978 that used to be Department of Mathematics and Physics in the School of Arts and Sciences. It offered Bachelors of Science degree with a major in physics, service courses such as physical science and other basic physics courses for engineering and other disciplines in the University. Later in the year 1978, one of the authors, Dr. R. B. Lal was awarded a major NASA grant to grow crystals in the microgravity of space. It may be mentioned that this NASA project was awarded even before the maiden voyage of the Space Shuttle. This achievement provided the inspiration and enthusiasm to the physics faculty to pursue a graduate program in the department. Fortunately, various federal agencies offer a wide range of funding opportunities for every aspect of initiating research that include young faculty awards to initiate research, funds to equip the undergraduate and graduate laboratories, major instrumentation awards for research equipment, research scholarships for undergraduate and graduate students for their studies leading to Bachelor's, Master's and Doctoral degrees in physics. Many of the faculty were motivated to increase their writing and submission of proposals to various agencies such as National Science Foundation (NSF) and the U.S. Army and several of these were funded. 


\section{Masters Program in Physics}

After that momentum and inspirational boost, some faculty in the physics department approached the administration to pursue Alabama Commission on Higher Education ${ }^{1}$ for granting us permission to initiate a Master's program in physics. Since we had many research projects from the Department of Defense, U.S. Army, National Science Foundation and NASA, the effort was made to write a proposal to Alabama Commission on Higher Education (ACHE) to initiate a MS degree program in physics, which was approved in $1981^{2}$. With the successful start of our M.S. Program, performance of space flight experiments in 1985 on the NASA Spacelab-3 mission and the help of Title III funds and individual projects, we successfully hired 3 post doctoral scholars around the year 1986.

\section{Doctoral Program in Physics}

With the help of Title III funds for graduate programs, a number of basic research equipment items needed at that time were procured for experimentation in the materials science and optics/lasers area. Based on the success of that time, we were able to attract one of the very renowned professors in optics and he initiated a flurry of activities in the optics area such as optical phase conjugation studies in nonlinear optical crystals, stimulated Raman studies in various media, and he attracted a number of post doctoral research associates and graduated a number of masters students during this period. The Physics faculty realized that without a Ph.D. program, growth of the department would be very limited especially in attracting large federal funding. After that, the physics faculty seemed to be well positioned and enthusiastic to further pursue their efforts for a proposal to the Alabama Commission for Higher Education for the doctoral degree program in physics. A proposal was generated and our administration was convinced about the benefit it would bring to our department, the university, and the country. At that time, there was only one $\mathrm{HBCU}$ which had a doctoral degree program in physics and if approved our university would be the second in the nation to have a Ph.D. program in physics among HBCUs. Fortunately our request was approved the second time around when our President Dr. Carl Marbury was present in the acceptance meeting. The Ph.D. program in physics at Alabama A\&M University was approved in the year 1986 because of the efforts of the dedicated faculty, and the support of the university administration. This was the first Ph.D. degree program in physics at our university and second in the country among HBCUs. It is worthwhile to mention that even now in the United States, we have only 4 universities offering Ph.D. programs in physics among HBCUs.

\section{Challenges after the approval of Doctoral Program in Physics}

Our department had very energetic faculty members and researchers who attracted a lot of research funding from NASA due to the visibility provided by the NASA initial experiment to grow crystals in the microgravity of space. A number of astronauts visited our campus and the department in connection with their training for the space experiment and our students had the opportunity of interfacing with them one on one. All these activities created a very collegial learning atmosphere for our students. The administration agreed to fund 3 doctoral fellowships and 3 masters fellowships for our graduate program and a couple of tenure track positions for initiating the doctoral program. In the beginning, we could get these scholarships, but after 2 
years, due to proration these were scrubbed and all the burden of funding the students came on the hard working faculty.

The administration kept changing at such a fast pace and the emphasis in HBCUs was purely on teaching undergraduate and graduate courses. Our faculty did not get any time release for guiding the thesis and dissertation of our graduate students pursuing their studies leading to masters and doctoral degrees in physics. Because of the land grant status of the university, other departments such as the Plant and Soil Science Department also had a lot of on going research and successfully got their doctoral program approved in the year 1988. Then another program in the School of Agricultural and Environmental Science, Food Science and Technology, got their program approved for a doctoral degree in 1992. These 3 programs helped Alabama A\&M University to be classified as a research intensive university according to the Carnegie classification $^{3-4}$. Some of the other institutions in this classification are Clark-Atlanta, Jackson State, South Carolina State, Tennessee State, and Texas Southern Universities. Howard University is the only HBCU classified as a Doctoral research extensive university. It was good to have this notoriety for the administration and the university could now qualify for higher salaries and increase their infrastructure funding mainly because of these graduate programs leading to Ph.D. degrees.

Our first Ph.D. student received his Ph.D. degree in optics in the year 1991 and since then the physics department at Alabama A\&M University has produced 56 doctoral students with a very limited number of faculty members. Due to the close proximity of NASA Marshall Space Flight Center and DOD establishments such as the U.S. Army Research Laboratory, U.S. Army Aviation and Missile Command, Space Missile Defense Command and many high technology companies, our department was able to attract a sizable funding for our students and was able to establish modern laboratories in materials sciences and optics/lasers with a minimum infrastructure. One of our professors was instrumental in establishing a Research Institute at Alabama A\&M University. The idea of establishing a Research Institute is to procure contracts and other fast turn around time and short-term projects from various companies and also to tap the SBIR and STTR opportunities in collaborations with the local high tech companies. This effort proved to be very successful and has been running since 1999. Another highlight of the department is the annual Nobel laureate lecture that was approved by the administration after the demise of one of the renowned Physics professors in the physics department and this lecture has been held every year for the last 9 years.

Another infrastructure related issue for our university is our slow central delivery system which is slow to the extent that you may get your supplies and equipment as late as 2 to 3 months. In the beginning, an immediate problem was a lack of space for establishing research laboratories, thus added facilities were needed. This was circumvented by writing a proposal with the help of the administration and that grant made it possible to build another new building that was completed in the 1988 time frame. This relieved some congestion for the physics faculty.

\section{Roles and Responsibilities of Graduate Faculty}

Graduate faculty members are required to fulfill teaching duties, be abreast of frontiers of knowledge, develop competitive research proposals, and publish research findings in national 
and international journals of physics. They also execute research experiments within the existing infrastructure as it currently exists, serve on Review Panels, peer review papers in scientific journals and serve on proposal review panels, initiate students in the methods of research, and guide M.S. and Ph.D. students pursuing their studies for their thesis and dissertations in various areas of physics. They should develop the graduate students as the stewards of the discipline. A steward is a scholar that can generate new knowledge, critically think and transform this knowledge through writing, teaching and application. They are also required to support students in their presentations and research papers. At present, no release time is provided for guiding master's and Ph.D. thesis/dissertation. Looking at the teaching loads of the other universities offering Ph.D. degrees, we always are striving to reduce our teaching load to 2 courses in the physics department, but we have not been able to achieve this goal. The faculty members are also required to be successful in procuring research funding and keeping their students supported.

\section{Nurturing Doctoral Programs at Alabama A\&M University}

During the past several years, the budgets of doctoral-granting departments have been reduced by at least $40 \%$. These budgets need to be restored and sufficient operating funds should be provided. Part of the indirect cost from grants/contracts should be given back to the department. Full-time support staff should be provided to maintain teaching laboratories and research infrastructure and there should be a reduction in the requirement for the cumbersome signature/approval process.

For graduate students, at the present time, out-of-state tuition should not be charged to all out-ofstate graduate students after one year of residence at the university. Tuition waivers should be given to all graduate students on assistantship or fellowships. Tuition rules should be similar to other state-supported institutions so Alabama A\&M University can recruit and support graduate students competitively.

\section{Need for more Ph.D.'s in Physics}

We receive calls and visits from various agencies such as the Coast Guard Academy and other universities such as Tennessee State seeking for African American Ph.D. for hiring for their teaching vacancies. It may be worthwhile to note that there are only 4 Ph.D. awarding HBCUs in the nation and they cannot possibly fill the need for Ph.D.'s in physics. We should be aggressive in nurturing these departments to produce more Ph.D.'s. NSF, NASA and other federal agencies also give high priority to help in increasing the number of minorities and African Americans to go in STEM disciplines and striving to address various pipeline issues for minority students.

\section{Physics Program at Alabama A\&M University}

The Ph.D. program was approved in 1986 and so far we have produced 56 Ph.D.'s which indicates that there are so many scientific topics researched and a lot of research work is done by a handful of faculty members. Each graduate student also was supported with about 100K during 4 years. As stated earlier, one of the Physics professors has helped in establishing a Research Institute at this university. Another physics professor has earned the status of the University Eminent Scholar, the only one at the university. He has flown 2 Space Flight Experiments on 
board NASA Space Shuttle missions. Three of our physics students have been selected for the USA Today All American team in 3 consecutive years. The department was awarded a prestigious NSF supported Center of Excellence in Nonlinear Optics and Optical Materials which was supported at a level of 10 million dollars for 10 years. One of our graduate students has been selected as Gates Millenium Scholar. There has been a yearly memorial lectures by Nobel Laureates for the last 9 years. Four of our graduate students have been invited to attend the Nobel Laureate meeting in Lindau, Germany since July 2002.

\section{Some suggestions for healthy growth}

For the program to stay healthy, the physics department needs to be provided with some nurturing ${ }^{5-7}$. Comparable teaching workload to those of other doctoral awarding institution should be provided to expect better results. Having a Ph.D. program places our university in a unique situation and our university is taken seriously and is currently classified as a research intensive university, although it may not necessarily be a money making enterprise. Tuition waivers should be given to good minority and other graduate students. More funding for teaching and research assistants should be provided for the first year entering students. Part of the indirect cost should be given back to the department. In-state and out of state tuition matter should be similar to other state institutions. An incentive plan for excellence in teaching and research should be revitalized.

A timeline of events for the graduate programs in physics at Alabama A\&M University is listed in Table 1.

\section{Table 1}

Timeline for graduate program in physics at Alabama A\&M University

\begin{tabular}{|l|l|}
\hline Aug 1978 & $\begin{array}{l}\text { NASA spaceflight experiment Spacelab-3 } \\
\text { award to AAMU }\end{array}$ \\
\hline May 1980 & $\begin{array}{l}\text { Proposal submitted to Alabama } \\
\text { Commission on Higher Education (ACHE) } \\
\text { for Master's degree in physics }\end{array}$ \\
\hline May 1981 & Proposal approved and program initiated \\
\hline May 1985 & $\begin{array}{l}\text { Proposal submitted to Alabama } \\
\text { Commission on Higher Education for } \\
\text { Doctoral Degree Program in physics }\end{array}$ \\
\hline May 1986 & $\begin{array}{l}\text { Proposal approved and program initiated } \\
\text { with specialization in materials science and } \\
\text { optics/lasers }\end{array}$ \\
\hline May 1991 & $\begin{array}{l}\text { First Ph.D. awarded. Presently serving at } \\
\text { Goddard Space Flight Center }\end{array}$ \\
\hline Til December 2006 & $\begin{array}{l}\text { 56 Ph.D. and 88 M.S. awarded and about } \\
\text { half of them are African Americans and } \\
\text { minorities }\end{array}$ \\
\hline
\end{tabular}




\section{Conclusions}

A brief history of challenges encountered in establishing the graduate program in physics leading to Masters and doctoral degree at Alabama A\&M University is discussed. In spite of all the benevolent positive intentions of the university administrators and the faculty, it takes a long time to improve the infrastructure from the traditional teaching culture to a research culture (Publish or Perish paradigm). This infrastructure and research facilities are needed for helping our graduate students to pursue their higher studies and the need to complete their thesis or dissertation for their masters and doctoral degrees in physics. Physics faculty has to work against the deep rooted perceptions of the public at large and prove ourselves at each step of the progress to university administrators as well as federal agencies.

A nucleus or core group of enthusiastic and motivated faculty members are needed to establish and carry out a successful doctoral program at an HBCU. It is not an easy task and is always an uphill battle with the administration and requires lots of persistent effort, but it can be accomplished and my kudos and commendations to the faculty of the physics department at Alabama A\&M University. In the future we hope to get some visionary administrators, and HBCUs/Minority institutions shall come into the main stream of having a strong research infrastructure and then high level research activity.

\section{Acknowledgements}

Two of the authors (MDA and RBL) wish to acknowledge the support from NASA Administrator's Fellowship program (NAFP) through United Negro College Fund special programs (UNCFSP) corporation under their contract \# NNG06GC58A.

\section{Bibliography}

1. Alabama Commission on Higher Education website: http://www.ache.state.al.us/

2. Richard D. Morrison (University President for 24 years) "History of Alabama A\&M University 18751992” Publishers: Liberal Arts Press, Huntsville, AL 1994.

3. http://www.carnegiefoundation.org/classifications/

4. The Carnegie Classification of Institutions of Higher Education (2000) A Technical Report By Alexander C. McCormick, Publishers: The Carnegie Foundation for the Advancement of Teaching, Menlo Park, CA 2001

5. Chris Golde and George Walker, Editors, Envisioning the Future of Doctoral Education: Preparing Stewards of the Discipline - Carnegie Essays on the Doctorate (2006) Publishers Jossey-Bass: An Imprint of Wiley San Francisco 2006

6. Daryl G. Smith, and Lisa E. Wolf-Wendel, The Challenge of Diversity: Involvement or Alienation in the Academy: ASHE Higher Education Report Vol 31, No. 1, 2005, publishers Jossey-Bass: An Imprint of Wiley San Francisco 2005

7. M. Edwards and A. Thompson, Establishing and Sustaining a Viable Research Program in Scholarly Guideposts for Junior Faculty (Quality Education for Minority Network, Washington, D.C. 2000) 